\title{
MANILA: EL MODELO COLONIAL ESPAÑOL EN ASIA
}

\author{
Miguel Situ Chang \\ Pontificia Universidad Católica del Perú \\ Msitu1@yahoo.com
}

\section{RESUMEN}

Hace más de quinientos años, durante el siglo XVI se produjo el encuentro entre chinos e ibéricos. Este acontecimiento sucedió en las Islas Filipinas durante la primera mundialización de la era moderna. Las dificultades financieras de los emperadores Ming coincidieron con el afán de riqueza de novohispanos y peruleros y la nueva ruta del Galeón de Manila por donde fluyó clandestinamente la plata americana. En este trabajo se analizará este proceso y su resultado, el modelo de colonización español en el Asia, el cual tuvo su mayor expresión, en la ciudad de Manila, en las relaciones entre "sangleyes" e hispanos.

\section{PALABRAS CLAVE}

Manila / Globalización temprana / Pacífico / Galeón de Manila / Comercio / Asia / Imperio Español

\begin{abstract}
More than five hundred years ago, in the 16th century, an important encounter between Chinese and Iberians took place. This happened in the Philippine Islands in the early stage of modern globalization. The financial difficulties of Ming Emperor, coincided with the desires for riches of the "Novohispanics" and "Peruleros", and the flux of clandestine American silver with the establishment of the Manila Galleon route. This present paper will analyze the aforementioned process and its result, the Spanish model of colonization in Asia, which particularly flourished in Manila with the relationship between Hispanics and Sangleys.
\end{abstract}

\section{KEYWORDS}

Manila / Early globalization / Pacific / Manila galleon / trade / Asia / Spanish Empire 
"El siglo XVI no se limita, por lo tanto, a la movilización de los recursos del Occidente al resto del orbe Es sintomático que el primer libro de historia política consagrado a Filipinas lo haya publicado Antonio de Morga en 1609 en las prensas de la capital mexicana Los límites reales o imaginarios de la dominación

ibérica, los mojones del 'inmenso resorte de la monarquía de España son desechados constantemente' (Serge Gruzinski "las cuatro partes del mundo")

"Sujetadas las islas, con la soberana luz del santo Evangelio, que en ellas entro, se baptizaron los infieles, desterrando las tinieblas de su gentilidad, y mudaron

sus nombres en el de Cristianos. Y dexando también las islas el que tenían, tomaron(con la mudanca de ley y baptismo de sus naturales) el nombre de Islas

Filipinas; en reconocimiento, de las grandes mercedes que recibieron, de la Magestaa de Filipo segundo nuestro señor; en cuyo felice tiempo y gobierno, fueron conquistadas, favorecidas y regaladas, como obra y hechura de sus Reales manos.

Su descubrimiento conquista y conversión, no ha sido sin mucha costa, trabajo y sangre Española."

(Antonio de Morga, Alcalde del Crimen, de la Real Audiencia de la Nueva España, Consultor del Santo Oficio de la Inquisición)

\section{LA CONQUISTA DEL LAGO ESPAÑOL}

En 1494, el Tratado de Tordesillas fue firmado por los reyes Isabel y Fernando de Castilla y el rey Juan II de Portugal delimitando las zonas de expansión y de conquista en el Océano Atlántico y en los espacios que Colón recientemente había identificado como territorios de las Indias. El proceso del descubrimiento y de la toma de posesión del Océano Pacífico se daría también bajo este y el Tratado producido en Zaragoza en 1529, los que permitieron delimitar las líneas de expansión ibérica en el Extremo Oriente.

Las expediciones de Colón dieron pie a diversas empresas de reconocimiento y demarcación en los nuevos territorios. El objetivo fue doble: poblar las islas encontradas y explotarlas económicamente. No obstante, el propósito de la Corona de Castilla era dar con las islas de la Especiería. Con esa intención en 1508, en la Junta de Burgos, Américo Vespucio recomendó armar una flota para proseguir con los hallazgos y con la expansión en el litoral centroamericano. Dicha incursión afrontaría la baja de varios de sus miembros por las dificultades durante la travesía oceánica y por los enfrentamientos en tierra firme con los nativos. Quienes resistieron tuvieron que refugiarse en la costa del Darién. 
Vasco Núñez de Balboa, fue uno de los refugiados, habiéndose convertido en jefe del asentamiento, logró una buena relación con los indios de la zona. Éstos le informaron de la existencia de otro mar muy cercano a donde se encontraban ofreciéndose como sus guías. Tras varias jornadas de caminata, el 25 de septiembre de 1513, Balboa y su destacamento lograron divisar la extensa masa de agua. El intrépido español denominó aquellas aguas como del Mar del Sur o Mar Austral, diferenciándolas del Mar del Norte correspondiente al Océano Atlántico, pues supuso que ambos mares eran el mismo océano que se encontraba dividido por el istmo de Panamá. Es así que, el 29 de septiembre de 1513, en el recién bautizado Golfo de San Miguel Núñez de Balboa proclamó a nombre de Fernando y Juana, reyes de la Corona de Castilla el descubrimiento, la posesión y la defensa del nuevo océano.

Este suceso marcó un hito, no solo para Castilla, sino también, para los demás reinos de Europa. El descubrimiento del Océano Pacífico por el mundo occidental abrió un ciclo expedicionario que permitió el reconocimiento continental de América y el establecimiento de nuevas rutas comerciales que posibilitarían conectar al mundo por la vía marítima. La empresa española resultó ser una conquista muy lucrativa al hallar una ruta más corta -gracias a los vientos y a las corrientes marinas- a las verdaderas Indias y, sobre todo, posibilitar la colonización de los territorios asiáticos. Los numerosos emprendimientos castellanos para lograr tales propósitos dieron cabida a contemplar al nuevo mar como el Lago Español.

Luego de una serie de expediciones, en 1520 Fernando Magallanes, quien se hace súbdito de la Corona, descubre el estrecho que le permite conectar el Atlántico con el Pacífico, y en 1521 sus navíos logran llegar a las Islas Filipinas -nombre que les dio en honor a Felipe II- y luego a las de las Islas Molucas. En el mismo 1521, Gil Gonzáles Dávila efectuó la primera expedición por la Mar del Sur llegando a las costas de lo que sería Costa Rica y Nicaragua. En 1522 Juan Sebastián Elcano completa el primer viaje de circunnavegación. Al mismo tiempo, García Jofre de Loaisa informaría de la casi imposibilidad de regresar por el nuevo mar a las Américas debido a los vientos y a las corrientes en contra. En la década siguiente, en 1535 las Islas Galápagos fueron descubiertas por Tomás de Berlanga.

Empresas posteriores, bajo la responsabilidad de Yñigo Ortiz de Retez, dieron a conocer en 1545 a Nueva Guinea. Las Islas Tuvalú y las Islas Salomón fueron bautizadas en 1568 por Álvaro de Mendaña. Y hacia principios del siglo XVI Quirós recorrería unas costas pobres en recursos por lo que no se les dio importancia pero que comprendían al aún desconocido continente australiano. 
Los exploradores castellanos, muchos de ellos sin las cartas ni las técnicas que los portugueses manejaban a la perfección, no tomaban aún conciencia del inmenso continente asiático. Las expediciones realizadas en años anteriores dieron cuenta del archipiélago filipino como punto de escala a otras costas de alta producción agrícola y de comercio fructífero como las de China, las de Japón, las colonias musulmanas en Borneo y el puerto portugués de Macao. Sin embargo, su descubrimiento solo cobraría importancia, si se encontraba la ruta de regreso a Nueva España que permitiría iniciar el ansiado comercio entre el Reino Castellano, a través de las colonias americanas, y; el continente asiático.

\section{COLONIZACION DE LAS FILIPINAS}

Tras numerosas expediciones, es mucho después de 1521, el año en que Magallanes descubre y toma posesión de las Islas, cuando se inicia el proceso de colonización de las Filipinas un 8 de mayo de 1565 bajo el mando del capitán general de la empresa Miguel López de Legazpi, quien fija el primer asentamiento en la localidad de Cebú en las Visayas ${ }^{1}$. Mientras ello acontecía, el marino Andrés de Urdaneta recibe la orden de regresar a los navíos y de partir para encontrar el tornaviaje hacia Nueva España, corresponde sin embargo, a Alonso de Arellano, acompañado del piloto Lope Martín el alcanzar la Nueva España en agosto de 1565 meses antes que Urdaneta, quien arriba a costas novohispanas recién en el mes de Octubre. (Bernabeu, p. 272 ). Ambos, en su travesía por las aguas del Pacífico norte se dirigieron hasta la latitud del Japón y en los $42^{\circ}$ Norte dieron con la famosa corriente del Kuro-Shivo con la que conseguirían trazar la ruta entre Filipinas y las Américas. El recorrido, si bien no fue el más corto, fue el más seguro y se mantendría por los dos siglos y medio de comercio que permitieron consolidar esta ruta como la ruta comercial de mayor duración en el tiempo, que hasta hoy, en pleno siglo XXI, sigue utilizándose y conectando a los países de mayor peso geopolítico.

La hazaña de la toma de posesión española, fue sucedida por años de enfrentamientos, tanto con los musulmanes quienes ya tenían tiempo en las costas de las islas tratando de conquistarlas, así como, con los jefes de las comunas nativas quienes se resistieron a la colonización. A ello se le sumaron los ataques de los piratas chinos y japoneses, además de la presión ejercida por Portugal, Inglaterra y Holanda en el área. Con todo, la Corona no daría marcha atrás y se mantendría constante en su objetivo: lograr presencia política, espiritual y económica en el

1 El archipiélago de Filipinas está conformado por tres islas: Luzón, las Visayas y Mindanao. 
continente asiático. Como colonia y como punto de escala hacia otros territorios, Filipinas era clave para los propósitos reales.

\section{LA CHINA DE LOS MING EN CRISIS}

Mientras tanto, que ocurría por esos años en el Asia, específicamente en China, allí gobernaba la dinastía Ming desde 1368. La segunda mitad del señorío de la dinastía Ming coincidió con la era de los grandes viajes de exploración europeos y con la época de la primera mundialización. Al inicio de los Ming, Europa no tenía aun una presencia en el Asia y China podía seguir contemplando el mundo exterior como hasta entonces, libre de potencias extrañas que le perturbaran el horizonte. (Levathes, p. 75). Los primeros emperadores Ming, de raíz campesina, no tenían ningún deseo de volver al sistema multi estatal de los Song; su meta era robustecer la posición central de China en el Asia Oriental según el modelo de las dinastías Han y Tang. Restablecieron el sistema de tributos, fundamentado en el emperador chino como figura central y con autoridad moral, era él, quien recibía los tributos y otorgaba las dádivas. Así, el emperador Taizu prohibió el comercio extranjero privado con la intención de que todo intercambio se efectuara dentro del marco de este sistema tributario. El emperador Chengzu envió emisarios a varios países potencialmente tributarios. Las misiones más grandiosas fueron los viajes marítimos de 1405 a 1433, dirigidos por uno de sus servidores de confianza, el eunuco musulmán Zheng He. Hemos escrito acerca de los viajes de Zheng He en otra ocasión, en esta oportunidad sólo señalaremos que se trataba de una inmensa flota compuesta por 62 barcos grandes y hasta 225 pequeños, el mayor de los cuales llegó a medir 135 metros, en la primera expedición participaron cerca de 27000 hombres y llegaron hasta Ormuz y la costa oriental de África. (Dreyer, p. 27).

El sistema tributario Ming solía funcionar óptimamente cuando se empleaba para regular las relaciones con estados pequeños o distantes. En cambio fue más difícil imponer este sistema en la frontera septentrional, ya que era porosa: había chinos asentados en territorio mongol y mongoles (muchos de ellos soldados del ejército Ming) asentados en China, y las guarniciones chinas realizaban comercio encubierto y contrabando con el enemigo. Además, China no dominaba militarmente esa frontera. Este sistema, además, conllevaba para China obligaciones paternalistas, como acudir en ayuda de estados vasallos leales que el gobierno Ming asumía, a veces, con un altísimo costo. (Brook, p. 219). En 1407 apoyaron a la dinastía Tran en Vietnam y de paso buscaron anexarse, sin éxito, el territorio. En el siglo XVI enfrentaron a la invasión japonesa de Hideyoshi en Corea, guerra en la que utilizaron de manera importante los mosquetes. (Buckley, p. 269). 
A pesar del poderío naval desplegado en las expediciones de Zheng He, en el tiempo de los Ming las fronteras marítimas, especialmente en el Sureste generaron tantos problemas para su defensa como las del Norte. En el siglo XVI la prohibición oficial del comercio tropezó con la construcción de una comunidad marítima de Asia Oriental formada por mercaderes y aventureros japoneses, portugueses, españoles, holandeses y chinos. Las relaciones con el exterior estaban estrictamente reglamentadas y controladas desde la corte imperial. Por ejemplo, todas las relaciones con Filipinas debían de pasar por la ciudad de Fuzhou, así como las de Japón por el puerto de Ningbo en Zhejian. Se ponían, además, límites a la frecuencia y al tamaño de las misiones diplomáticas. Los mercaderes a menudo se convertían en contrabandistas debido a los controles oficiales. Los barcos cargados de mercancías atraían a los piratas, ya fueran estos chinos o japoneses, los cuales, se convirtieron en una plaga en toda la costa a mediados del siglo XVI. Los esfuerzos de los Ming no tuvieron éxito hasta que a la represión armada se acompañó con un relajamiento en las normas que impedían el comercio.

El palacio y la corte imperial china, sin embargo, gastaban a manos llenas el dinero, el derroche para mantener la estabilidad imperial, los agasajos, la edificación de las tumbas imperiales costaban millones, para esto último se procuraba que los materiales proviniesen de los mejores centros de producción y de las provincias tributarias en los cuatro puntos cardinales, los cuales estaban alejados del centro imperial. (Fairbanks, p.168). En 1523, el reinado del emperador Shi Zong experimentó agudas crisis financieras. Las rentas anuales por concepto de impuestos no sobrepasaban los dos millones de taeles de plata, pero en 1551 los gastos llegaron a 5.950.000. Los ingresos no podían cubrir ni el 50\% de los gastos, el emperador tenía manía por la construcción monumental, en sus primeros 15 años de reinado invirtió de 8 a 10 millones de taeles de plata en este renglón. A los gastos suntuarios, se agregaban los gastos de las rentas entregadas a los parientes de la familia imperial. El emperador Hongwu, tuvo 24 hijos, el emperador Wanli, 45 príncipes de primer rango, el príncipe de Qincheng nada menos que 94 descendientes en línea directa, la nobleza imperial había aumentado hasta tener 23000 nobles de rango menor. Todo este conjunto implicaba otorgar prebendas, privilegios, predios, tierras de pastos, guardias personales, obsequios para evitar cualquier intento de usurpación, lo cual se llevaba el más alto porcentaje del cobro de los impuestos debiendo suspenderse en determinado momento los permisos de matrimonio y el otorgamiento de más títulos de nobleza. Uno de los emperadores Shen Zong, alrededor de 1590, llegó a gastar 9.340.000 taeles de plata en la ceremonia realizada para conferir los títulos a su primogénito y en la celebración de sus bodas, mientras que los ingresos por concepto de impuestos a la tierra no llegaban a los 4 millones por año. (Shouyi, pp. 335-349). 
Esto nos lleva a examinar las transformaciones que se estaban produciendo al interior de la economía en el sistema imperial chino. A finales del siglo XIV, en un momento en que la economía china sufría las destrucciones provocadas por las guerras civiles y el combate contra los mongoles, la mayoría de las transacciones se hacían en especie y lo esencial de los recursos provenían de las entregas en cereales exigidas a los campesinos. Sin embargo, durante la China de los Ming se sigue procediendo, como se había hecho desde el siglo XI, a recurrir a las emisiones de papel moneda, interviniendo el estado para aplicar el uso de los billetes de varias maneras; impone la compra con billetes de las monedas de cobre en 1394, prohíbe el uso de la plata y del oro en las transacciones en 1403, recurre al pago de los funcionarios en billetes. Sin embargo, el papel moneda no convertible, se devaluaba rápidamente y sólo podía mantenerse al precio de injusticias y de actos arbitrarios por parte del estado y de sus agentes, así, se suspende su emisión a partir de 1450 y sólo se reanuda muy raras veces, la circulación continúa hasta cerca de 1573 y luego, en 1643 se imprimen los últimos billetes antes de la época contemporánea, concluyendo con una institución que fue la primera en el mundo pero, que luego, durante la dinastía de los manchúes, fue sinónimo de mala administración. Triunfa, en el uso práctico, el lingote de plata frente al billete y en el intercambio se impone desde principios del siglo XV. El pago del impuesto a la sal, el de los tributos de las provincias, el de las tasas que eximen de los trabajos obligatorios tanto para los artesanos como para los campesinos, todo se realizaba en lingotes de plata. Entre 1570 y 1580 se llevaron adelante unas reformas fiscales bajo el nombre del "latigazo único" integrando impuestos, (Fairbanks, p.171). gabelas y servicios en uno solo que se pagaba en plata, así, se simplificaban las prácticas fiscales para prevenir el abuso y extender la tributación, pero al mismo tiempo, se legalizaba también, el uso extendido de los lingotes y de las monedas de plata como medio de pago puesto que los campesinos no podían pagar en especie, sino que sus cereales debían cambiarlos por la plata, sufriendo de todas maneras una carga adicional por la intermediación. "En el temprano siglo XVI, por ejemplo, el ratio oro/plata era en Europa 1:12, 1:10 en Persia, y 1:8 en la India, mientras que en China era de 1:6" (Von Glahn, 1996 p. 433). "Más tarde en 1590, el ratio oro/plata fue 1:5.5 o 1:7 en Cantón mientras que en España era 1:14 lo cual indicaba que el valor de la plata era el doble en China" (Flynn, p. 87).

Por otro lado, pese a que estamos inclinados a considerar a la China de los Ming como un poder monolítico centralizado y organizado bajo una burocracia hegemónica, lo real es que las provincias del Sur como Fujian, Guangdong y Zhejian siempre mantuvieron sus distancias del centro imperial, diferencias que provenían, de su antigua conformación con otras etnias y reinos como el legendario 
reino Nam del sudeste asiático; diferenciación que las llevó a desarrollar dinámicas muy complejas que les permitiría conexiones independientes con Japón, con Corea, con las islas Ryukyu, con las Filipinas, con la parte insular del Sudeste Asiático y establecer fuertes lazos entre Guangdong y Luzón. En este panorama, el incremento de la presión demográfica que se mantenía a distancia del crecimiento económico, la pobreza de las tierras, difíciles de roturar, en tanto el mayor porcentaje del territorio de la provincia de Fujian está constituido por estribaciones de montañas que llegan hasta el mar y; la necesidad del arroz como alimento principal, cereal que se cultiva en planicies inundadas, empujó a la población del sudeste costero de China, pese a las prohibiciones y castigos y antes que los demás a los Fujianenses, a llegar a Manila con propósitos comerciales.

\section{EL ENCUENTRO DE CHINOS E IBÉRICOS.}

Fueron los portugueses los primeros ibéricos que establecieron contacto con China desde Malaca, esto ocurrió en 1514, casi sesenta años antes que los españoles; (Li JingMing, p. 9), a lo largo de estas seis décadas organizaron una red de puertos que activaban y monopolizaban rutas comerciales de ámbito regional a través de sus enclaves en Malaca, los territorios de la especiería de las islas Molucas y los puertos de Macao y Nagasaki, los portugueses aportaban, una experiencia de asentamiento comercial en las rutas del Océano Indico y del Sudeste Asiático, tuvieron la fortuna y el manejo suficiente para ser tolerados y ser bienvenidos en Japón desde 1543, esto les permitió aprovechar el impasse diplomático que cortó las relaciones entre China y Japón para convertirse en el único operador en la carrera de la Nao da Prata como le llamaron a la intermediación entre el Japón y China. El producto que los portugueses más ansiaban de China fue la Seda y esta la obtenían en Macao, a cambio de ello, llevaban los lingotes de plata de Japón a China (Loureiro, p. 88), en un negocio de intercambio con grandes beneficios hasta que fueron desplazados por los holandeses en la primera década del siglo XVII. Los estimados de exportación de plata de Japón hacia China entre 1550 y 1645 varían entre 3622 y 3802 toneladas métricas del mineral. (Massarella, p. 8).

En el Océano Indico y en el Sureste Asiático existía una centenaria tradición de presencia activa de diásporas y de comunidades mercantiles procedentes de ámbitos lejanos que, en numerosas ocasiones, ocupaban posiciones de élite de poder en ámbitos costeros estratégicos (árabes, persas, armenios, chinos, etc.). Esta flexibilidad, esta capacidad de absorción y de aceptación de comunidades mercantiles extranjeras en tareas de dirección o de intermediación eran características de la zona del Asia marítima; y ello explica la facilidad con la que se introdujeron los 
portugueses en el espacio de las rutas comerciales del Índico y del Sudeste asiático y determinó los parámetros en los que generalmente interactuaron. A pesar de que la expansión colonial portuguesa asiática se orientaba en una dirección más marítima y comercial que territorial y tributaria, se apoyaba también en una acción militar, aunque restringida, del control de las ciudades y de puertos estratégicos para el establecimiento de la Carreira de India en sus diferentes tramos. Tras décadas de enfrentamientos, contrabando, embajadas fallidas, apresamientos y prisioneros, en la provincia de Guandong las autoridades locales encontraron finalmente una fórmula legal y pragmática, de diplomacia regional, para permitir la presencia estable de los portugueses a partir de 1557. (Fukuda, p. 105).

\section{CONQUISTADORES CONQUISTADOS}

A principios del siglo XVI las primeras incursiones españolas en el Asia buscaron desplazar a los portugueses del control del mercado de las especies que se generaba en las islas Molucas, no fue sino hasta 1565 en que arriban a las Filipinas cuando surgen las interrogantes acerca de si considerarla un lugar de asentamiento definitivo o sólo como una plataforma para la expansión hacia China. Aparentemente, Miguel López de Legázpi se inclinaba por pasar hacia China, las cartas de consulta dirigidas a Felipe II y al virrey de México iban en ese camino. Líneas arriba vimos como el primer asentamiento español se produce en la isla de Cebú ubicada hacia el área sur del conjunto isleño, desde allí Legazpi se desplaza hacia el Norte a la isla de Panay y desde allí hacia la isla de Luzón, adonde envía más de una expedición que tras luchar contra los piratas chinos y derrotar la resistencia de los nativos toman el próspero asentamiento musulmán denominado Mayniland sobre el cual fundan la ciudad de Manila el 24 de Junio de 1571. La intención de Legazpi fue trasladarse de Cebú a la bahía de Manila por tener cerca una zona agro productiva -de tierras arroceras-, por estar más cerca al continente chino y a los sultanatos de las islas de Borneo, y contrariamente por estar alejada de las Molucas desde donde Portugal ejercía presión. Para Legazpi, la Corona debería pretender cosas de más calidad que las especias y eso pasaba por China.

En Mindoro una isla cercana a Manila, Legazpi encuentra 30 chinos que habían sido hecho esclavos por los nativos filipinos, los compra, les da la libertad y les proporciona una embarcación para su regreso a casa, en Manila encuentra una comunidad de 40 chinos algunos de los cuales habían conocido el cristianismo, convirtiéndose y bautizándose en Japón, estableció con ellos una buena comunicación e igual que los anteriores les da obsequios y acepta los suyos, Legazpi preparaba con cierta visión "antillana", la conquista del continente, se ubica geográficamente lo más 
cerca de China desplazándose al Norte, va recogiendo toda la información posible y estableciendo vínculos con el continente. (Ollé, 2013, p. 319). Los eclesiásticos coincidían en similar visión, el provincial de los agustinos, Martín de Rada, el primer embajador del gobernador de Filipinas en China, consideraba que fácilmente y no con mucha gente los chinos podían ser dominados, sin embargo, después que en 1575 conoce la provincia de Fujian visita el territorio, calibra el volumen de la población y el desarrollo de los asentamientos, cambia de opinión, al igual que Legazpi ambos van adquiriendo una visión más completa de la realidad a la cual se intentaban aproximar, en el camino matizaron sus opiniones, y del afán de conquista violenta van adquiriendo una posición pragmática que tendió a predominar en las relaciones entre chinos y españoles en las Filipinas. (Iaccarino, p. 80).

El sucesor de Legazpi, Guido de Lavezaris envió en 1575 otra embajada también dirigida por Martín de Rada a Fujian con la intención de un acercamiento y establecer una línea de comercio, el momento era propicio porque tanto españoles como chinos enfrentaban un enemigo común, el pirata chino Limahon, sin embargo este logra escapar, los acercamientos se diluyen, a lo cual contribuye Francisco de Sande, el nuevo gobernador de Filipinas, uno de los más firmes partidarios del asentamiento español en China por la vía de las armas, acabando con la política de acercamiento anterior. (Concepción, Juan de la, p. 3). En esa línea, el jesuita Alonso Sanchez diseñó un proyecto de conquista de China que fue estudiado oficialmente, junto a un memorial de peticiones, por la Corona, Felipe II accedió a muchas de las peticiones pero rechazó con rotundidad el proyecto de conquista de China. (Ollé, 2002 p. 82).

"Al final, resultó que fueron los españoles de Manila los que resultaron conquistados de forma sutil por los chinos. Manila acabó convertida en una floreciente y mercantil ciudad poblada mayoritariamente por chinos con una pequeña élite dominante española”. (Ollé, 2013 p. 323). Ahora bien, la Monarquía Universal conseguida por Felipe II al proclamarse rey Felipe I de Portugal en 1581, reduciría la amenaza de pugnas entre Manila y las colonias portuguesas del área. No obstante, si bien los acuerdos tomados consideraban la absoluta separación de las administraciones coloniales y la prohibición de comercio entre ambas, los intercambios entre los castellanos en Manila y los portugueses en Macao serían tan frecuentes como sus ambiciones de expansión territorial y económica. (Lourido, p. 23).

De esa manera, con el puerto de Manila instaurado se iniciaba un periodo agitado de comercio que permitiría ampliar los intercambios ya existentes y establecer nuevas rutas entre el Viejo y Nuevo Mundo y el continente asiático. 
Como hemos podido apreciar, uno de los objetivos del establecimiento en las Filipinas fue la presencia castellana en China y su conquista, aspiración que resultó no solo imposible sino caricaturesca. ${ }^{2}$ Habiendo superado este anhelo, el establecimiento de una ruta comercial de especias se planteó como alternativa. Canela, pimienta, jengibre entre otras serían enviadas a Nueva España y al Perú. Sin embargo, Filipinas no era tan productiva como otras islas de la zona. Sus especias no podían competir en precio con las de las colonias portuguesas, la economía nativa era prácticamente de subsistencia y, además, no había suficiente mano de obra. Los recursos poco lucrativos y el exceso de una población no productiva entre conquistadores castellanos e inmigrantes chinos que salían de un imperio Ming en problemas en busca de mejores horizontes sólo llevaban a una crisis económica. Ante ello, el relativamente estable comercio de los chinos asentados en las Islas dio pie a que se pensara en la comercialización a gran escala de productos chinos con los virreinatos americanos a cambio de metales preciosos como la plata lo cual nos lleva a examinar en que consistió la actividad del parián de Manila.

\section{EL PARIAN DE MANILA}

La navegación por las rutas comerciales del Asia Sudoriental y del Mar de China estaba marcada por los ritmos estacionales de las corrientes y de los monzones, los navegantes y los comerciantes chinos, debían adaptarse a ellos para arribar a las costas adonde realizaban el intercambio, así como debían de tenerlos en cuenta para el regreso a sus lugares de origen, los chinos de Fujián que se dirigían hacia Luzón, Borneo, Java o Sumatra navegaban con los monzones del noreste que arrecian entre noviembre y febrero, mientras en la ruta de retorno que seguían también los comerciantes procedentes del sureste asiático navegaban con los impulsos de los monzones del suroeste, que llegaban a las costas chinas hacia finales de la primavera y el verano. (Deng, 2011).

La estacionalidad de la navegación, obligaba a los mercaderes chinos a permanecer unos meses en los puertos de destino de los mares del sur, esperando la aparición de los monzones que guiasen sus naves de retorno a la costa continental china. Este fue un factor importante que incentivó la reconversión de los flujos comerciales en flujos migratorios. En el caso de los intercambios que tenían como principal objetivo, la obtención del preciado mineral, de la plata que llegaba desde las remotas costas mejicanas y peruanas, los tiempos de espera eran mucho más prolongados e inestables, lo cual incentivó el proceso migratorio y el asentamiento

2 Para conocer más sobre el intento de conquista del Imperio China revisar OLLE, Manel 2002. 
chino en Manila. Legazpi encuentra inicialmente 30 esclavos y 40 comerciantes chinos, al siguiente año eran 150 y a lo largo del siglo XVI la presencia china fue haciéndose cada vez más abundante y preponderante, hasta que en determinado momento eran 2000 españoles en un recinto amurallado rodeados por cerca de 30000 chinos a los cuales contemplaban con una mezcla de necesidad y temor. (Ollé, 2003).

En lengua tagalo Parián significa mercado y esto es lo que se establece en Manila, un mercado de la seda, una alcaicería que estaba compuesta por los mercaderes y por la población china que se habían ido estableciendo y asentado dentro de las fronteras de este dominio español.

\section{LOS SANGLEYES: EXTRANJEROS NECESARIOS}

¿Cómo estaba considerado el chino dentro de este marco? Los españoles eran conscientes de la inviabilidad de Manila sin la presencia de los chinos. Al inicio, ambas poblaciones se confundían y compartían el territorio; conforme el proceso del conocimiento mutuo se fue desarrollando, este terminó por decantarse en un entendimiento pragmático, en ningún momento los chinos fueron considerados ni se consideraron súbditos. Estos siempre se incorporaron como extranjeros en pie de igualdad, es ilustrativa la anécdota del primer acercamiento de los chinos que se hallaban en Manila, cuenta que, comerciantes chinos fueron llevando alimentos y presentes, modestos, pero significativos a la primera partida de españoles guerreros que llegaron, el fin era buscar su amistad y establecer una posible relación comercial.

Al inicio Legazpi, cuando avanzó desde Cebú hasta Luzón, los denominaba "indios chinos", es posible que utilizara esta categoría en su correspondencia con la Corona, anticipando una posibilidad de conquista y de avasallamiento tal como había sucedido con los indios americanos y los recién incorporados filipinos, sin embargo no pasó mucho tiempo antes de que dejara de referirse a ellos como tales y los empezara a denominar como chinos, luego "chinos sangleyes" y por último "sangleyes" a secas sin el apelativo de Indios.

La palabra "sangley" tiene antecedentes en la expresión china "shanglai" (los venidos a comerciar) o bien al término "sengli" que significa comercio en el dialecto fujianes, o como lo señala el segundo teniente gobernador Francisco de Sande "...por todas estas yslas los llaman sanleyes, ques nombre como quen dize gente que va y viene, por la costumbre que tienen de yr y venir cada año a estas yslas a contratar", es decir un derivativo de la expresión china "changlai" (los que vienen con frecuencia). (Ollé, 2006 p. 42). 
Los chinos se van estableciendo en la recién fundada ciudad y la abastecen con alimentos, construyen edificios, se desenvuelven como plateros, zapateros, cerrajeros, herreros y en general, servían a la comunidad española de Manila de todo lo que pudiera desear. Al final, hasta se especializaban en productos que no eran de la tradición cultural china pero que demandaba el mercado español, tales como; imágenes religiosas cristianas o tipos de tejidos que llegaron a hacerse populares en América y en España, así tenemos, a los famosos mantones de Manila, una prenda que probablemente la hacían los chinos para venderla a los españoles de Filipinas.

Así, a pesar de que los intentos diplomáticos por acercarse a China y los planes militares para su conquista fracasaron; los chinos y los españoles terminaron encontrándose en las Filipinas. Cientos de chinos llegaban cada año con la mercadería que el Galeón debía embarcar, cruzar el Pacífico y vender en Acapulco. Conforme pasaba el tiempo la población china, probablemente empujada por los factores de crisis en el continente, los cuales señalamos líneas arriba, fue espoleada cada vez más a buscar un mejor destino fuera del mismo, el asentamiento en Manila tenía un crecimiento exponencialmente superior a las expectativas de los españoles, se llegó fijar una cantidad límite de 6000 chinos, pero esta cifra fue sobrepasada con largueza, para 1603, 25000 sangleyes pululaban en el parián, evidentemente, vivir en Filipinas resultaba más atractivo que en las costas de Fujian. (Ollé 2006, García-Abásolo 2011).

En ese entorno las relaciones de chinos e ibéricos se desarrollaban en un clima de constante tensión, pero de mutua necesidad, Manila era el lugar donde durante meses se iba acumulando mercadería y productos chinos sobre todo la preciada seda y la porcelana, toda la población española participaba en el negocio, todos tenían o buscaban un espacio de donde obtener utilidad en las travesías del galeón, desde las autoridades del Cabildo, hasta los Cabildos abiertos que se convocaban para determinar las participaciones. Este gran entrepôt como ha sido denominado era sustentado por los sangleyes del parián quienes basados en sus relaciones familiares de clan obtenían la producción de las ciudades costeras del sureste chino sorteando los peligros que conllevaban las continuas expediciones imperiales para saquearlos o para prohibirles el comercio, pero eran esas mismas relaciones ancestrales de clan lo que les permitía crear las redes que los volvían competitivos en producción, transporte y empacamiento que asombraron y motivaban a españoles, comerciantes de Nueva España y peruleros a proseguir con el negocio que bordeaba, en buena medida, en el límite de la legalidad. (Diaz de Seabra, p. 46).

Entre los españoles de Manila se reconocía que la presencia china era necesaria pero al mismo tiempo se abominaba de ellos, se les temía y se les despreciaba, 
se les aislaba en un ghetto cerrado, a modo de judería o de morería, y además, situados a tiro de artillería desde la ciudad amurallada y del que de noche no podían salir sin incurrir en pena de muerte, solamente los chinos de la panadería del Cabildo podían dormir en el interior de la Manila amurallada, pero la panadería era en sí misma, un fortín con muros y rejas en donde se les encerraba. Si la opinión frecuente acerca de los tagalos filipinos era que representaban a la molicie en el caso de los chinos se insistía en que "...son gente mala y viciosa, y con su trato y comunicación, los naturales medran poco en su cristiandad".(Morga, p. 168 (354/368)). Esta descripción casi generalizada del carácter de los chinos de Manila contrasta con las descripciones casi utópicas que se hacían del Imperio chino (Lara Vilá, p. LXV). como un lugar ordenado, rico y civilizado, al cual sólo le faltaba la cristianización. Esa percepción de los gobernadores castellanos en Filipinas llevaba invariablemente a la intención española de expulsarlos pero que terminaban con la realidad de la dependencia que la comunidad española tenía de los sangleyes para sobrevivir, con el correr del tiempo la imagen del chino se fue perfilando como original, comerciante, hábil artesano de cualquier oficio, buen agricultor y pescador y; acaparador de moneda de plata.

Sin embargo, las costumbres y las creencias de los chinos fueron una fuente permanente de conflicto, especialmente desde el punto de vista religioso, en 1592, el gobernador Gómez Pérez Dasmariñas prohibió las celebraciones por el año nuevo chino porque se trataba de extranjeros que venían a sembrar idolatrías y supersticiones en tierras cristianas, la otra fuente de conflicto la constituían los intentos de reclutamientos forzosos de contingentes de chinos para las campañas de "pacificación" a lo largo de las islas Filipinas, en 1582 hubo un primer intento de rebeldía, en 1592 una expedición embarcada de 250 chinos, se amotinó y terminó asesinando al gobernador Pérez Dasmariñas.

Los alzamientos y las rebeliones de los sangleyes responden a circunstancias históricas precisas en todos los casos "el desequilibrio demográfico es determinante en la tensión que explota en forma de violencia destructiva: el reducido núcleo de unos cuantos centenares de españoles armados y custodiados en la ciudad intramuros se sienten permanentemente amenazados por la populosa y floreciente comunidad china de la que viven en todos los sentidos y que les supera más que largamente en número". (Ollé, 2006 p. 45). Otras razones lo son, la segregación racial, el toque de queda, las restricciones al retorno a China o al asentamiento en otras regiones de Filipinas, el recelo y el abuso fiscal, mercantil o judicial reiterado, los continuos intentos de cristianización y las intervenciones en las relaciones de clan familiar que constituían por si mismas un tejido aparte dentro de la comunidad y en su relación con el continente. En resumen, un conjunto de acciones que respondían a 
visiones culturales diferentes, en un escenario de permanente construcción tratando de establecer un equilibrio entre las partes. (Ollé, 2013).

La primera rebelión de los sangleyes ocurrió en 1603 tras la visita de una nave imperial china a Manila. Aquel año los sangleyes ascendían en número a 21,000 , estuvieron dispuestos a dar muerte a todos los españoles y liquidaron efectivamente a muchos de ellos, la represión con artillería e infantería produjo una gran mortandad y casi llevó al exterminio de la población de sangleyes, sin embargo para 1606 la población se había reconstituido, la segunda gran rebelión ocurrió en 1639 ante la pretensión del gobernador Hurtado de Corcuera de que los habitantes del parián se dediquen al cultivo del arroz en los campos de las inmediaciones para el abastecimiento de Manila. Los sangleyes que ya estaban bastante agobiados por el alquiler de sus viviendas, de sus talleres, de sus locales de comercio y de los impuestos, se negaron a participar y estalló la violencia. La tercera rebelión ocurrió en 1662 cuando el pirata Zheng Chonggong o Koxinga envió un requerimiento de tributo y sometimiento, el gobernador español, previniendo la existencia de aliados en el interior de Manila intentó expulsar a la comunidad china, la cual ofreció resistencia con la consiguiente represión y exterminio. La cuarta rebelión, en 1686, tuvo que ver con el cambio dinástico en China. (Concepción, Juan de la). Los resultados del enfrentamiento por la sucesión hicieron que miembros de la facción derrotada, llegaran a las islas acompañados de bandidos y merodeadores. los que desataron saqueos, tumultos y violencia, enfrentando una vez más a chinos y españoles, con la matanza consiguiente. (Ruiz- Stovel, Ollé 2006).

Sin embargo, no es una historia de buenos y malos, es una historia de desencuentros etnocéntricos, de desencuentros culturales, religiosos y producto de la permanente tensión que ya hemos señalado, se advierte con recurrencia que tras cada masacre hay un repoblamiento, que a su vez este se incrementa en número, lo cual indica que los españoles luego de cada masacre hacían todo lo posible para reproducir la población masiva del Parián y de que los comerciantes e inmigrantes chinos aceptaban los riesgos de convertirse en las víctimas de la siguiente masacre, lo cual indica la potencia del atractivo mercantil de Manila.

\section{EL MODELO COLONIAL ESPAÑOL EN FILIPINAS}

En un texto muy ilustrativo Antonio García-Abásolo (García-Abásolo, 2005), analiza los recursos utilizados por el Imperio español para desarrollar un sistema capaz de integrar territorios muy alejados, con patrones económicos, sociales y culturales muy diversos, y las dificultades que la administración colonial tuvo que resolver para mantener la integridad del conjunto del Imperio que con la 
expansión a través del Pacífico hacia las Filipinas, la cual constituyó una primera experiencia de mundialización.

Un primer elemento a considerar, fue el de los recursos para mantener una administración colonial mundializada pese a las dificultades de la distancia que no permitían la información y la comunicación adecuada. "En el mejor de los casos la conexión Manila- Madrid-Manila suponía un tiempo de tres años", (García-Abásolo, p. 1846), a lo cual se añadían las dificultades del legislador para entender realidades complejas y de territorios remotos que muchas veces no eran bien reflejadas e informadas por los administradores coloniales. Un sabio recurso, en estos casos fue dejar un prudente margen de seguridad ante posibles errores de interpretación, salvando la responsabilidad de la autoridad colonial. La conocida fórmula "se obedece pero no se cumple" era muy socorrida en estos casos. Un ejemplo claro en las Filipinas fue la Real Cédula del 14 de Noviembre de 1686 para expulsar a los chinos no cristianos, la Real Audiencia dispuso siete meses para su cumplimiento y esta se llevó a efecto en 70 años, quedando muchos chinos infieles en el territorio.

Un segundo elemento lo constituyó la necesidad de ser pragmáticos y flexibles para la interpretación de las leyes, de tener una burocracia colonial prudente, lo cual era un principio válido para las relaciones del gobierno de Madrid con las provincias, así como la de los administradores de provincias con la población, en el caso de las Filipinas el cobro de los almojarifazgos a los comerciantes chinos tuvo que aplicarse muy progresivamente, al principio se les pasaba por alto, luego progresivamente se iba aplicando e incrementando, aun cuando las declaraciones de los valores se llevaban sólo de palabra y sin inspección, con el mutuo beneficio del patrón de la nave y el funcionario, similar era en el caso del galeón de Manila, cuyo exceso en las cargas originó más de un naufragio. Cada vez que se pretendía imponer la rigurosidad, la población española de Manila amenazaba con abandonar Filipinas y establecerse en México o regresar a España, los hechos cotidianos debían estar impregnados de tal flexibilidad incluso en hechos más triviales como el permiso que debía otorgar la Corona a sus funcionarios para casarse con mujeres de la zona, aducían los interesados que si no contraían matrimonio antes de recibir el permiso corrían el riesgo de perder la opción frente a las pocas mujeres españolas que habían disponibles. Puede decirse que el Imperio se gobernó con un sistema administrativo que mostró su eficacia por la versatilidad y por su capacidad de adaptación a situaciones de mundos diversos y complejos.

El tercer elemento a tener en cuenta fue, como asegurar el dominio con súbditos leales que garantizasen la lealtad a la Colonia en un territorio con tan 
poca población española. Un tema muy complejo en el caso de Manila. El territorio filipino tenía una reducida presencia de metales preciosos y la explotación de la tierra para la producción de consumo no tenía sentido con un mercado español tan reducido. La viabilidad de la presencia española en Asia dependía de poder encontrar una actividad que pudiese atraer población de México y España. El poblamiento era dificultoso por la lejanía, la falta de incentivo de las riquezas y las dificultades del suelo y del clima considerado malsano y consumidor para los hispanos. La parcial solución a este problema se la proporcionaron los chinos, ellos con sus mercaderías de bajo costo y alta demanda y sus necesidades de plata proporcionaron el incentivo comercial y además, con su presencia proporcionaron la mano de obra y los recursos cotidianos para el sostenimiento de Manila. Lo que no pudieron resolver fue el tema demográfico, puesto que las familias de españoles se acababan a las pocas generaciones, constituyendo una constante preocupación.

En torno al mestizaje y a la integración con los mestizos, debido a lo reducido de la población española no se puede hablar de un fenómeno extendido, sin embargo, este factor, el reducido número y el recelo permanente a los chinos, a quienes, como ya vimos líneas arriba, nunca se consideraron ni fueron considerados, parte integrante de la población, sino siempre como una población extranjera, hizo que los mestizos en Filipinas, debido a sus componentes tanto físicos como culturales, fueran más apreciados y valorados en Filipinas que en el resto de las posesiones coloniales españolas.

El elemento que más diferenciaba las características del Imperio español de otras visiones de conquista, era el tema del contenido religioso del proceso, esta pauta le da un sello particular desde la bula Inter coetera de 1493. La evangelización le imprime un espíritu de cohesión, que en el caso de las Filipinas, fue la vía para el asentamiento de una administración española consolidada, "dentro del imperio se estableció una corriente de dotación de suministros a las provincias deficitarias, por medio de asignaciones oficiales de dinero llamados situados. Filipinas recibió por años un situado anual de las Cajas Reales de México, y los motivos que justificaron el pago de este precio fueron razones estratégicas y el mantenimiento de la evangelización". (García-Abásolo p. 1861). En lo que se refiere al trato con los chinos, ya señalamos que estos siempre fueron considerados extranjeros, por ello se les exigía el pago de una licencia de radicación que costaba mucho más que el tributo exigido a los naturales. Por iniciativa de los dominicos, sin embargo, se emitió una Real cédula ordenando que los sangleyes convertidos dejaran de pagar durante diez años y al cabo de ese tiempo sólo pagarían igual que los nativos. Una muestra más del pragmatismo de las relaciones entre chinos y españoles por la 
certeza que ambos tenían de la dependencia mutua. Señalábamos líneas arriba que en el espacio mental español los chinos ocupaban un lugar similar a los judíos y musulmanes en España, en Filipinas los religiosos procuraron convertir a musulmanes y chinos y muchos se oponían a su expulsión teniendo el recuerdo de las consecuencias económicas que conllevó la expulsión morisca de la península.

La difusión del español en Filipinas no alcanzó los niveles de América, la poca presencia de población española y mestiza en una ciudad tan exótica como Manila donde, como hemos podido observar, los controles y las normas del Imperio eran más flexibles y pragmáticas permitió la presencia de una población más cosmopolita, para lo cual acudimos a la descripción de dos religiosos para entender el contexto. El agustino Joaquín Martínez de Zúñiga a principios del siglo XIX nos dice: "Manila, la ciudad con sus extramuros y arrabales, tendrá 100.000 almas de españoles, mestizos, indios, chinos, armenios, ingleses, franceses y de otras naciones, pues casi no hay casa de gente en el mundo que no tenga en Manila algunos individuos. Los dueños son los españoles, que son muy pocos porque no llegan a 1000 familias, aun contando como españoles muchos que tienen alguna mezcla de otra sangre. La población principal son los indios y mestizos de chino, que pagan al rey su tributo, tienen sus gobernadorcillos y están sujetos al corregidor de Tondo", (García-Abásolo, p. 1864), por otro lado, refiriéndose al aspecto de la lengua el padre Pedro Murillo que vivió en Manila a mediados del XVIII, nos dice: "Estando una hora en el Tuley o Puente de Manila se verán pasar casi todas las naciones de Europa, Asia, América y África: se verán sus trajes y se oirán sus lenguas. El prodigio es que todos estos para comunicarse entre si hablan en español; pero como. Cada nación ha formado una jerigonza por donde se entienden. Yo oí un día un gran pleito entre un sangley, un armenio, y creo que un malabar, todos hablaban español y yo no entendía a ninguno, por no haber estudiado entonces sus vocabularios". (García Abásolo, p. 1865). También la lengua hubo de adaptarse, tuvo que generarse un modo pragmático de comunicarse en la vida diaria de Manila.

Por último, hay que tener en cuenta, que cuando se aplica el concepto indio, la administración colonial lo utiliza en el sentido de súbdito de la Monarquía Hispánica, esto se trató de aplicar en un primer momento a los chinos, cuando las intenciones de conquista miraban al continente, luego se limitó sólo a los filipinos, los chinos nunca fueron considerados vasallos, se les consideraba extranjeros, lo cual en una sociedad cerrada y estamental era difícil de aceptar, sobre todo cuando hacían y acumulaban riqueza. Pese a ello, fueron considerados extranjeros necesarios, imprescindibles para poner en marcha el mecanismo del comercio marino que daba sentido a la reducida presencia española como a la subsistencia de la misma, en otras palabras a la existencia de Manila. 


\section{CONCLUSIONES}

Con el descubrimiento y la posesión del Océano Pacífico, España y sus colonias, que constituían el mundo ibérico, adquirieron una posición estratégica desde la cual dieron inicio a una temprana globalización en el siglo XVI. Con la ruta del Atlántico establecida y con el Pacífico descubierto, ya en el siglo XVI, las "cuatro partes del mundo" estaban conectadas vía marítima.

En el inicio del establecimiento en Filipinas, tanto los primeros gobernadores civiles como los evangelizadores religiosos, con un espíritu "antillano" la consideraron una plataforma para abordar la conquista del continente, donde China con sus fabulosas y utópicas riquezas se consideraba el objeto del deseo de los ibéricos, la realidad del conocimiento de los territorios y de las fuerzas que pretendían gobernar hizo cambiar la visión conquistadora hacia una actitud pragmática y comercial.

La China de los Ming atravesaba, en la época en que arribaron los castellanos a Filipinas, por una crítica situación económica que la llevó a suspender su sistema monetario y adoptar la plata como patrón de intercambio, convirtiéndose en una voraz succionadora de lingotes de cualquier procedencia. Hasta ese momento el principal abastecedor era Japón con quien sus relaciones eran de continua tensión.

Esto llevó a establecer el negocio del intercambio de plata proveniente de México y Perú e intercambiarla por mercadería china en la recién fundada Manila que así se convirtió en el entrepôt, en el gran almacén de intercambio de productos entre Asia y el Nuevo Mundo.

La dinámica comercial llevó a la coexistencia de más de dos siglos de españoles y chinos en el Parián de Manila, coexistencia que estuvo marcada la colaboración y el enfrentamiento, por el recelo y la admiración de dos culturas y de dos posiciones etnocéntricas marcadas y diferentes, pero también por el mutuo convencimiento de la inviabilidad del centro de intercambio y de la posesión colonial sin la presencia de ambos.

Para la Monarquía Hispánica significó adaptar su modelo colonial a las flexibilidades y al pragmatismo que exigía enfrentar el gobierno de un Imperio ecuménico, "la eficacia del sistema estuvo en su capacidad para depositar en las autoridades coloniales unas interpretaciones flexibles que salvaban los problemas generados por la distancia y que producían una relativa centralización de funcionamiento lento, pero eficaz la administración colonial fue capaz de aplicar una moderna actitud 
pragmática, de alguna manera similar a los recursos que en la actualidad se desarrollan para solventar los problemas suscitados por la globalización". (García-Abásolo, p. 1867).

\section{REFERENCIAS BIBLIOGRÁFICAS}

Bernabéu Albert, S. y Martinez Shaw, C. (eds.) (2013). Un océano de seda y plata: el universo económico del Galeón de Manila, Sevilla: Consejo Superior de Investigaciones Científicas.

Brook, T. (2010). The Troubled Empire. China in the Yuan and Ming Dynasties, The Belknap Press of Harvard University Press.

Buschmann, R. F., Slack Jr., E. R., Tueller, J. B. (2014). Navigating the Spanish Lake, The Pacific in the Iberian World, 1521-1898, Honolulu: University of Hawai'I Press.

Buckley Ebrey, P. (2009). Historia de China Cambridge, España: La Esfera de los Libros.

Canales, C. y Del Rey, M. (2015). Naves negras. La ruta de las Especias, España: Edaf

Concepcion, J. (1788). Historia General de las Philipinas, Tomo II, http://archive. org/details/historiageneral00juan_3

D'avila Lourido, R. (2003). “Portugueses e Espanhóis em Macau e Manila com os Olhos na China" en Revista de Cultura, International Edition 7, Julho/July, 2003, Instituto Cultural do Governo da Regiao Administrativa Especial de Macao.

Deng, H. and Li, X. (2011). "The Asian Monsoons and Zheng He's Voyages to the Western Ocean”, THE JOURNAL OF NAVIGATION. 64, 207-218, The Royal Institute of Navigation.

Diaz De Seabra, L. (2003). "Power, Society and Trade. The Historic Relationship between Macao and the Philippines from the $16^{\text {th }}$ to $18^{\text {th }}$ Centuries" en Revista de Cultura, International Edition 7, Julho/July, Instituto Cultural do Governo da Regiao Administrativa Especial de Macao. 
Dreyer, Edward L. (2007). China and the Oceans in the Early Ming Dinasty: 14051433, New York: Pearson Educations, Inc.

Fairbanks, J. (1996). China, una nueva historia, Santiago de Chile: Editorial Andrés Bello.

Flynn, D. and Giraldez, A. (2004). "Path dependence, time legs and the birth of globalization: A critic of O'Rourke and Williamson", European Review Economic History.

Fukuda, K. (2002). "The relations between China and Portugal in the Early Sixteenth Century. Some observations on the Yue Shan Cong Tan" en Revista de Cultura, International Edition 1, Janeiro/January, 2002, Instituto Cultural do Governo da Regiao Administrativa Especial de Macau.

Garcia-Abasolo, A. (2015). "Problemas para gobernar un imperio. Aspectos del modelo colonial en Filipinas, siglos XVI-XVII" en Revista de Estudios Extremeños, Tomo LXXI, Badajoz: Centro de Estudios Extremeños.

Gernet, J. (2007). El Mundo Chino, Libros de Historia, Barcelona: Crítica

Gruzinski, S. (2010). Las cuatro partes del mundo. Historia de una mundialización, México: Fondo de Cultura Económica

Gunder Frank, A. (2008). Re-Orientar. La economía global en la era del predominio asiático., Universitat de Valéncia.

Iaccarino, U. (2008). "Manila as an International Entrepôt", Bulletin of Portuguese - Japanese Studies, vol 16, Junio, 2008 pp. 71-81 Universidade Nova de Lisboa.

Lara Vilá, T. (2009). "Viajes y Crónicas de Oriente en el Siglo de los descubrimientos" en Viajes y Crónicas de China, Córdoba: Editorial Almuzara

Levathes, L. (1998). When China ruled the Seas, New York: Oxford University Press.

Li, Jingming, (2002). "Actividades dos Portugueses nos mares da China nos primórdios da demanda da Asia" en Revista de Cultura, International 
Edition 1, Janeiro/January, 2002, Instituto Cultural do Governo da Regiao Administrativa Especial de Macau.

Loureiro, R. (2002). "As Origens de Macau nas Fontes Ibericas" en Revista de Cultura, International Edition 1, Janeiro/January, 2002, Instituto Cultural do Governo da Regiao Administrativa de Macau.

Martinez, J. (2014). El descubrimiento de China. La última gesta española del Siglo de Oro, Madrid: Catarata

Massarella, D. What was Happening in East Asia around 1600? Faculty of Economics, Tokio: Chuo University.

Morga, A. (1609). Sucesos de las Islas Filipinas dirigido a Don Cristoval Gomez de Sandovaly Rojas, México, http://archive.org/details/sucesosdelaisla00morg

O'phelan Godoy, S. (2005). Passeurs, mediadores culturales y agentes de la primera globalización en el Mundo Ibérico, siglos XVI - XIX, Lima: Pontificia Universidad Católica del Perú.

Ollé, M. (2002). La Empresa de China, Barcelona: Acantilado.

Ollé I Rodriguez, M. (2003). “A insercao das Filipinas na Ásia Oriental (15651593)" en Revista de Cultura, International Edition 7, Julho/July, 2003, Instituto Cultural do Governo da Regiao Administrativa Especial de Macau.

Ollé, M. (2006). "Capítulo 2. La formación del parián de Manila: La construcción de un equilibrio inestable" en La Investigación sobre Asia Pacífico en España, Granada.

Ollé, M. (2013). "El imperio chino ante los Ibéricos de Asia Oriental" en Ruiz Ibáñez, José Javier, Las vecindades de las comunidades ibéricas, Madrid: Fondo de Cultura Económica.

Ruiz-Stovel, G. (2009). "Chinese Merchants, Silver Galleons and Ethnic Violence in Spanish Manila, 1603-1668", Análisis Vol. 12, núm. 36/ septiembre diciembre de 2009. 
Shouyi, B. y otros (1984). Breve Historia de China - Desde la Antigüedad hasta 1919, Beijing: Ediciones en Lenguas Extranjeras.

Spate, O.H.K. (2006). El Lago Español, España: Casa Asia.

Von Glahn, R. (1996). "Myth and Reality of China's Seventeenth-Century Monetary Crisis", The Journal of Economic History, Vol.56, N²2, Jun.

Von Glahn, R. (2014). "Chinese Coin and Changes in Monetary Preferences in Maritime East Asia in the Fifteenth-Seventeenth Centuries", Journal of the Economic and Social History of the Orient 57. 